\title{
Endothelial dysfunction in subjects with chronic cadmium exposure
}

\author{
Pinanong Lukkhananan ${ }^{1}$, Natthapong Thawonrachat ${ }^{1}$, Sirada Srihirun ${ }^{2}$, \\ Witaya Swaddiwudhipong ${ }^{3}$, Ganyapong Chaturapanich4, Pornpun Vivithanaporn5, \\ Supeenun Unchern ${ }^{5}$, Pornsawan Visoottiviseth ${ }^{6}$ and Nathawut Sibmooh ${ }^{5}$
}

\author{
${ }^{1}$ Toxicology Program, Faculty of Science, Mahidol University, Rama 6 Road, Bangkok, 10400 Thailand \\ ${ }^{2}$ Department of Pharmacology, Faculty of Dentistry, Mahidol University, Bangkok, 10400 Thailand \\ ${ }^{3}$ Department of Community and Social Medicine, Mae Sot General Hospital, Tak Province, 63110 Thailand \\ ${ }^{4}$ Department of Physiology, Faculty of Science, Mahidol University, Rama 6 Road, Bangkok, 10400 Thailand \\ ${ }^{5}$ Department of Pharmacology, Faculty of Science, Mahidol University, Rama 6 Road, Bangkok, 10400 Thailand \\ ${ }^{6}$ Department of Biology, Faculty of Science, Mahidol University, Bangkok, Rama 6 Road, 10400 Thailand
}

(Received November 18, 2014; Accepted July 22, 2015)

\begin{abstract}
Vascular endothelium is a target of cadmium (Cd) toxicity. Cd exposure has been reported to be associated with vascular disorders. In this study, we aimed to investigate the effects of Cd exposure on markers of endothelial function in human subjects chronically exposed to Cd. Based on blood $\mathrm{Cd}$ levels, seventy-five women were categorized into non-exposed, Cd-exposed and severely Cd-exposed groups. Nitrite, L-arginine, asymmetric dimethylarginine (ADMA), and soluble thrombomodulin levels in blood were measured. Nitrite levels were lower in Cd-exposed subjects than non-exposed subjects. Plasma L-arginine decreased while ADMA, an endogenous endothelial nitric oxide synthase (eNOS) inhibitor, increased in Cd-exposed subjects. Soluble thrombomodulin also increased in Cd-exposed subjects. In Cd-exposed subjects, plasma malondialdehyde and protein carbonyl groups increased while the erythrocytic glutathione decreased. Multiple linear regression analysis revealed a negative association between urinary $\mathrm{Cd}$ and nitrite levels in erythrocytes. Our research suggests that subjects with chronic $\mathrm{Cd}$ exposure have endothelial dysfunction.
\end{abstract}

Key words: Cadmium, Nitrite, Soluble thrombomodulin, ADMA, Endothelial dysfunction

\section{INTRODUCTION}

Environmental Cd contamination causes a significant health problem. In addition to renal tubular dysfunction and osteoporosis, $\mathrm{Cd}$ exposure contributes to the development of cardiovascular diseases. The increased prevalence of hypertension and kidney diseases has been reported in the areas contaminated with Cd such as Mae Sot District, Tak Province in the northwestern part of Thailand (Swaddiwudhipong et al., 2012). High urinary Cd was found to be associated with mortality and incidence of cardiovascular diseases such as coronary artery disease, heart failure and stroke (Tellez-Plaza et al., 2013).

Evidence suggests that the vascular wall is also a target of $\mathrm{Cd}$ deposition. $\mathrm{Cd}$ deposited in vascular wall of smokers at concentration up to $20 \mu \mathrm{M}$ as compared to the blood concentration of low nM range (Abu-Hayyeh et al., 2001). In vitro exposure of endothelial cells to $\mathrm{Cd}$ $(15 \mu \mathrm{M})$ resulted in the increased permeability, inhibition of cell proliferation and induction of cell death (Messner et al., 2009). Cd induced hypertension in rats, which involved oxidative stress and suppression of eNOS expression in blood vessels leading to impaired acetylcholineinduced vasorelaxation (Yoopan et al., 2008; Donpunha et al., 2011). Rats treated with $\mathrm{Cd}$ had increased response to vasopressor phenylephrine, and increased expression of NADPH oxidase in endothelial cells (Almenara et al., 2013). However, the change in endothelial function markers by $\mathrm{Cd}$ had never been reported in human.

In this study, we hypothesized that subjects with chronic $\mathrm{Cd}$ exposure would have impaired endothelial function. Blood nitrite was measured as an index of nitric oxide (NO) production by endothelial cells. Stimulation of eNOS in human forearm vessels resulted in increased

Correspondence: Nathawut Sibmooh (E-mail: nathawut.sib@mahidol.ac.th) 


\section{P. Lukkhananan et al.}

nitrite concentrations in plasma (Lauer et al., 2001) and whole blood (Dejam et al., 2005). eNOS inhibition resulted in a decrease in plasma nitrite concentration, and eNOS knockout mice had lower plasma nitrite compared to wild-type mice (Kleinbongard et al., 2003). Soluble thrombomodulin was measured as a marker of endothelial damage in which its elevated levels were associated with endothelial dysfunction and thrombosis (Ishii et al., 1991; Bouman et al., 2014; Sharma et al., 2014). ADMA is an endogenous eNOS inhibitors and its high levels are associated with vascular disorders (Böger et al., 1998; Tripepi et al., 2011). Moreover, oxidative stress was determined by the levels of lipid and protein oxidation in plasma, and reduced glutathione in erythrocytes.

\section{MATERIALS AND METHODS}

\section{Subjects and baseline clinical parameters}

This study was approved by the Ethical Clearance Committee on Human Rights to Research Involving Human Subjects, Faculty of Medicine Ramathibodi Hospital, Mahidol University, based on the Declaration of Helsinki. Cd concentrations in whole blood and urine were measured by atomic absorption spectrometry (AAnalysis 600, PerkinElmer, Waltham, MA, USA). Baseline clinical laboratory parameters were determined at Laboratory of Mae Sot General Hospital. Seventy-five nonsmoker women living in Mae Sot District, Tak Province, Thailand were enrolled in the study and categorized according to their previously recorded blood $\mathrm{Cd}$ levels into non-exposed ( $n=25$, blood $\mathrm{Cd}<0.5 \mu \mathrm{g} / \mathrm{L})$, Cd-exposed $(n=25$, blood Cd 1-5 $\mu \mathrm{g} / \mathrm{L})$ and severely Cd-exposed $(n=25$, blood $\mathrm{Cd}>5 \mu \mathrm{g} / \mathrm{L})$ groups (Prozialeck and Edwards, 2010). All subjects were in clinically stable state. Subjects with hypertension, heart diseases and diabetes mellitus were excluded from the study.

\section{Measurement of nitrite, nitrate and soluble thrombomodulin}

Fasting venous blood samples were collected using heparin (143 units/10 mL) as an anticoagulant. Whole blood samples were mixed immediately with the nitritepreserving solution containing $0.8 \mathrm{M}$ ferricyanide, $10 \mathrm{mM}$ N-ethylmaleimide and 1\% NP-40 in a 5:1 dilution (Dejam et al., 2005; Pelletier et al., 2006). Meanwhile, whole blood samples in other tubes were quickly centrifuged at $2000 \mathrm{~g}$ for $1 \mathrm{~min}$ at $4^{\circ} \mathrm{C}$ to separate erythrocytes and plasma. Within $2 \mathrm{~min}$, the erythrocytes were mixed with the nitrite-preserving solution. All samples were stored at $-80^{\circ} \mathrm{C}$. Nitrite levels in whole blood, erythrocytes and plasma were measured by triiodide-based chemilumi- nescence (Yang et al., 2003). Nitrite and S-nitrosothiols reacted with triiodide reagent to release NO gas that was detected by a chemiluminescence NO analyzer (Eco Medics Analyzer CLD88, Duernten, Switzerland). Nitrite was distinguished from S-nitrosothiols by pre-treating samples with $5 \%$ acid sulfanilamide as acid sulfanilamide formed a complex with nitrite that was not reduced to NO in triiodide reagent. Addition of acid sulfanilamide to samples abolished the chemiluminescence signal completely, indicating that the majority of signal represented nitrite levels. Plasma nitrate concentrations were measured by vanadium chloride-based chemiluminescence (Yang et al., 2003). Area under the curve was calculated using Origin 7 (Microcal Software, Inc., Northampton, MA, USA).

To confirm the presence of endothelial dysfunction, soluble thrombomodulin in plasma was measured by ELISA (Abcam, Cambridge, UK). Elevated soluble thrombomodulin in plasma is indicative of endothelial injury (Tohda et al., 1998; Sharma et al., 2014).

\section{Determination of L-arginine, ADMA and SDMA by high-performance liquid chromatography}

In order to assess the endothelial activity regarding NO synthesis, we also determined the plasma levels of L-arginine (a substrate for eNOS), ADMA (asymmetric dimethylarginine or $N^{\mathrm{G}}, N^{\mathrm{G}}$-dimethyl-L-arginine, an eNOS inhibitor and maker of endothelial dysfunction) and SDMA (symmetric dimethylarginine or $N^{\mathrm{G}}, N^{\prime \mathrm{G}_{-}}$ dimethyl-L-arginine, an inhibitor of L-arginine uptake). L-arginine, ADMA and SDMA in plasma were measured by high-performance liquid chromatography (Teerlink et al., 2002) consisting of Water Alliance 2695 Separation Module (Waters Corporation, Milford, MA, USA) and a FP-2020 fluorescence detector (Jasco, Easton, MD, USA). Chromatographic separation was achieved at $35^{\circ} \mathrm{C}$ on AccQ-Taq column (4 $\mu \mathrm{m}, 3.9 \times 150$ mm; Waters $)$. Monomethylarginine was used as an internal standard. L-arginine, ADMA and SDMA were extracted from plasma by solid phase extraction using Oasis MCX SPE columns (Waters). Then, the samples were washed with $1 \mathrm{~mL}$ of $100 \mathrm{mM} \mathrm{HCl}$ and methanol. L-arginine, ADMA and SDMA were eluted with concentrated ammonia/water/ methanol (10/40/50) and evaporated with $\mathrm{N}_{2}$ at $60-80^{\circ} \mathrm{C}$. The samples were re-dissolved in $0.1 \mathrm{~mL}$ of water and derivatization reagent. Separation was performed with mobile phase consisting of $93 \% 50 \mathrm{mM}$ potassium phosphate buffer and 7\% acetonitrile at flow rate of $0.8 \mathrm{~mL} /$ min for $19 \mathrm{~min}$. The column was washed with $50 \%$ acetonitrile in water for $20 \mathrm{~min}$ before injecting the next sample. Fluorescence was detected at $340 \mathrm{~nm}$ excitation and 
Endothelial dysfunction in Cd-exposed subjects

$455 \mathrm{~nm}$ emission.

\section{Measurement of lipid peroxidation, protein carbonyl groups and reduced glutathione}

Plasma malondialdehyde, a lipid peroxidation marker, was measured by spectrofluometric method using thiobarbituric acid assay (Ohkawa et al., 1979). Plasma protein carbonyl groups, markers of protein oxidation, were measured by commercial ELISA kit (BioVision, Milpitas, CA, USA). Reduced glutathione in erythrocytes was measured by colorimetric method (Beutler et al., 1963).

\section{Statistical analysis}

PASW Statistics 18 (SPSS Inc., Chicago, IL, USA) and GraphPad Prism 4 (GraphPad software Inc., San Diego, CA, USA) were used for statistical analysis. Comparison analysis was performed by Analysis of Variance (ANOVA) with Tukey's multiple comparison test. Multiple linear regression analysis was used to explore the relationship between endothelial function markers and the potential independent variables. $p$ value $<0.05$ was considered significantly different.

\section{RESULTS}

\section{Baseline subjects' characteristics}

Seventy-five women were enrolled in the study; 25 subjects in each group. There was no difference in age and systemic blood pressure among the groups (Table 1). Cd-exposed and severely exposed subjects had no difference in serum ferritin, calcium, zinc, creatinine, blood urea nitrogen, hemoglobin, white blood cell count, platelet count, and urinary $\beta_{2}$-microglobulin. Both exposed groups had higher levels of serum creatinine, blood $\mathrm{Cd}$, urinary $\mathrm{Cd}$, and urinary $\beta_{2}$-microglobulin than the non-exposed group. Severely exposed subjects had higher triglyceride levels than non-exposed subjects. The high-density lipoprotein cholesterol (HDL-C) and serum zinc levels were lower in both $\mathrm{Cd}$-exposed groups than those in non-

Table 1. Subjects' characteristics.

\begin{tabular}{|c|c|c|c|}
\hline Parameters & Non-exposed & Cd-exposed & Severely Cd-exposed \\
\hline$n$ & 25 & 25 & 25 \\
\hline Age (years) & $48.4 \pm 1.2$ & $50.9 \pm 2.3$ & $51.4 \pm 1.7$ \\
\hline Systolic blood pressure (mmHg) & $123.7 \pm 2.6$ & $118.4 \pm 2.9$ & $127.0 \pm 3.7$ \\
\hline Diastolic blood pressure (mmHg) & $74.3 \pm 2.3$ & $75.2 \pm 1.3$ & $78.1 \pm 1.3$ \\
\hline Mean arterial blood pressure $(\mathrm{mmHg})$ & $90.8 \pm 2.3$ & $89.6 \pm 1.6$ & $94.4 \pm 1.9$ \\
\hline Serum ferritin $(\mathrm{ng} / \mathrm{mL})$ & $100.2 \pm 20.9$ & $59.2 \pm 7.4$ & $84.7 \pm 14.7$ \\
\hline Blood urea nitrogen (mg\%) & $10.8 \pm 0.6$ & $11.3 \pm 0.7$ & $11.1 \pm 0.6$ \\
\hline Serum creatinine $(\mathrm{mg} \%)$ & $0.67 \pm 0.02$ & $0.96 \pm 0.04^{\mathrm{a}}$ & $0.90 \pm 0.02^{\mathrm{a}}$ \\
\hline Serum calcium (mg\%) & $8.63 \pm 0.11$ & $9.62 \pm 0.06^{\mathrm{a}}$ & $9.60 \pm 0.08^{\mathrm{a}}$ \\
\hline Serum zinc $(\mu \mathrm{g} / \mathrm{dL})$ & $91.1 \pm 1.81$ & $77.8 \pm 2.1^{\mathrm{a}}$ & $75.6 \pm 1.6^{\mathrm{a}}$ \\
\hline Total cholesterol (mg/dL) & $204.3 \pm 11.7$ & $240.8 \pm 14.0$ & $183.5 \pm 11.5$ \\
\hline HDL-C (mg/dL) & $57.6 \pm 3.7$ & $47.2 \pm 2.1^{\mathrm{a}}$ & $42.1 \pm 2.3^{\mathrm{a}}$ \\
\hline LDL-C (mg/dL) & $124.8 \pm 9.8$ & $159.6 \pm 15.5$ & $121.6 \pm 6.8$ \\
\hline Triglycerides (mg/dL) & $136.2 \pm 15.0$ & $177.4 \pm 20.3$ & $204.8 \pm 20.1^{\mathrm{a}}$ \\
\hline Hemoglobin (g/dL) & $13.5 \pm 0.4$ & $12.5 \pm 0.2$ & $12.4 \pm 0.3^{\mathrm{a}}$ \\
\hline White blood cell $\left(10^{3} / \mu \mathrm{L}\right)$ & $6.43 \pm 0.42$ & $6.78 \pm 0.28$ & $7.14 \pm 0.40$ \\
\hline Platelet count $\left(10^{3} / \mu \mathrm{L}\right)$ & $248.1 \pm 14.8$ & $236.7 \pm 14.8$ & $242.8 \pm 12.7$ \\
\hline Blood Cd $(\mu \mathrm{g} / \mathrm{L})^{\mathrm{c}}$ & $0.31 \pm 0.25$ & $3.97 \pm 2.05^{\mathrm{a}}$ & $8.48 \pm 3.85^{\mathrm{a}, \mathrm{b}}$ \\
\hline Urinary $\mathrm{Cd}(\mu \mathrm{g} / \mathrm{g} \text { creatinine })^{\mathrm{c}}$ & $0.32 \pm 0.30$ & $3.40 \pm 1.58^{\mathrm{a}}$ & $9.56 \pm 3.93^{\mathrm{a}, \mathrm{b}}$ \\
\hline Urinary $\beta_{2}$-microglobulin $(\mu \mathrm{g} / \mathrm{g} \text { creatinine })^{\mathrm{c}}$ & $34.0 \pm 36.0$ & $119.6 \pm 148.7^{\mathrm{a}}$ & $140.5 \pm 197.2^{\mathrm{a}}$ \\
\hline
\end{tabular}

Values are mean \pm S.E. of subjects with blood $\mathrm{Cd}<0.5$ (non-exposed), $1-5$ (Cd-exposed) and $>5 \mu \mathrm{g} / \mathrm{L}$ (severely Cd-exposed). ${ }^{a} p<0.05$ vs. non-exposed group. ${ }^{b} p<0.05$ vs. Cd-exposed group (ANOVA with Tukey's multiple comparison test). ${ }^{\mathrm{c} D a t a}$ are expressed as geometric mean \pm geometric S.D. HDL-C, high-density lipoprotein cholesterol; LDL-C, low-density lipoprotein cholesterol. 
exposed group. The blood and urinary Cd levels showed significant correlation (Pearson $r=0.65, \mathrm{p}<0.0001$ ), and were higher in severely exposed than exposed subjects. For unclear reason, Cd-exposed subjects had higher serum calcium levels than non-exposed subjects.

\section{Nitrite and nitrate}

The baseline nitrite levels in plasma, erythrocytes and whole blood were lower in severely exposed subjects than non-exposed subjects (mean \pm S.E.; $31.8 \pm 4.0$ vs. $69.1 \pm$ $7.3 \mathrm{nM}, 47.0 \pm 3.4$ vs. $195.0 \pm 11.6 \mathrm{nM}$ and $93.6 \pm 5.9$ vs. $155.5 \pm 12.7 \mathrm{nM}$, respectively; $\mathrm{p}<0.05$ ) (Fig. 1). In Cd-exposed group, only the erythrocytic nitrite showed a significant reduction compared to non-exposed group $($ mean \pm S.E.; $96.7 \pm 13.1$ vs. $195.0 \pm 11.6 \mathrm{nM} ; \mathrm{p}<0.05)$ (Fig. 1C). There was no difference in plasma nitrate levels among the three groups. The plasma nitrate levels (mean \pm S.E.) in non-exposed, exposed and severely exposed groups were $11.7 \pm 0.8,13.5 \pm 1.2$ and $12.8 \pm 0.8 \mu \mathrm{M}$, respectively.

A

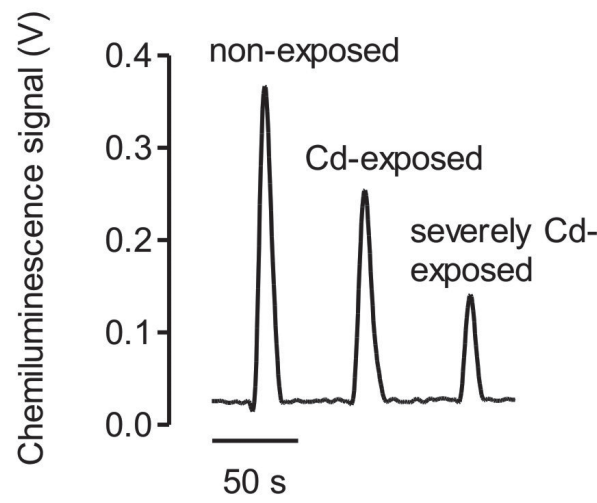

C

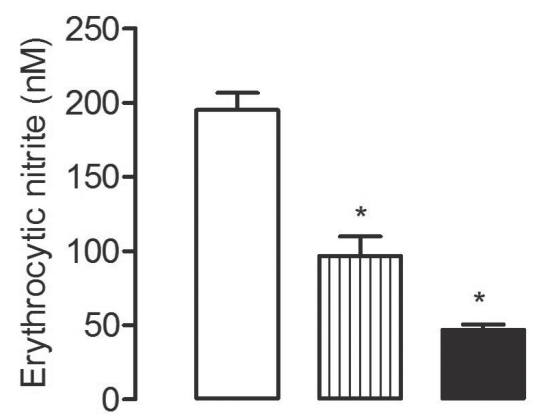

\section{L-arginine, ADMA, SDMA, and soluble} thrombomodulin

Further, we examined L-arginine availability and levels of ADMA and SDMA. Both Cd-exposed groups had lower L-arginine plasma levels than non-exposed group (Fig. 2A). L-arginine levels (mean \pm S.E.) in non-exposed, exposed and severely exposed groups were $280.3 \pm 30.6$, $167.9 \pm 8.4$ and $185.1 \pm 9.0 \mathrm{nM}$, respectively. Plasma ADMA concentrations were higher in severely exposed groups than non-exposed group (mean \pm S.E.; $0.57 \pm 0.08$ vs. $0.30 \pm 0.05 \mu \mathrm{M} ; \mathrm{p}<0.05$ ) (Fig. $2 \mathrm{~B}$ ). There was no difference in plasma SDMA concentrations (Fig. 2C). Raised levels of soluble thrombomodulin in both Cd-exposed groups were observed (Fig. 2D).

\section{Oxidative stress}

Because oxidative stress could lead to a decrease in NO availability, we measured malondialdehyde and protein carbonyl as markers of lipid and protein oxidation, respectively. Plasma concentrations of malondialdehyde

\section{B}

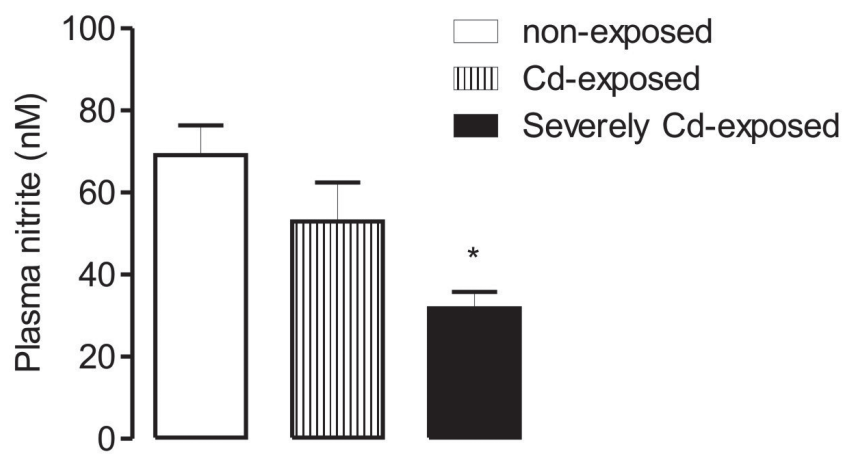

D

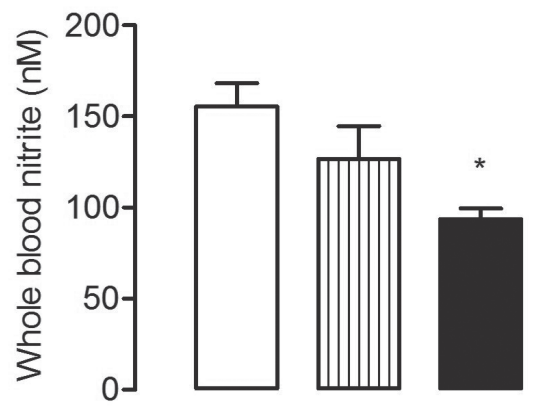

Fig. 1. Baseline nitrite levels in blood. (A) Representative traces of chemiluminescence signals of the erythrocytic nitrite. Nitrite levels in plasma (B), erythrocytes (C) and whole blood (D) of non-exposed, Cd-exposed and severely Cd-exposed subjects. Data are presented as mean \pm S.E. ${ }^{*} \mathrm{p}<0.05$ vs. non-exposed group (ANOVA with Tukey's multiple comparison test). 
Endothelial dysfunction in Cd-exposed subjects

A
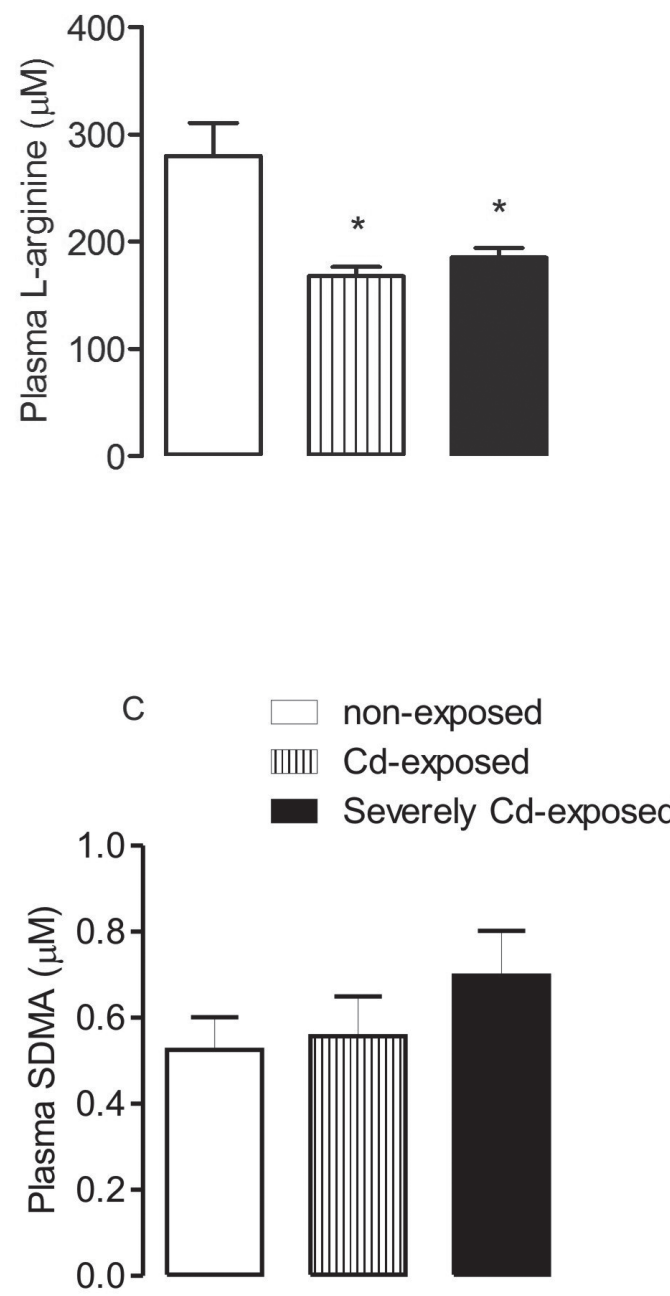

B

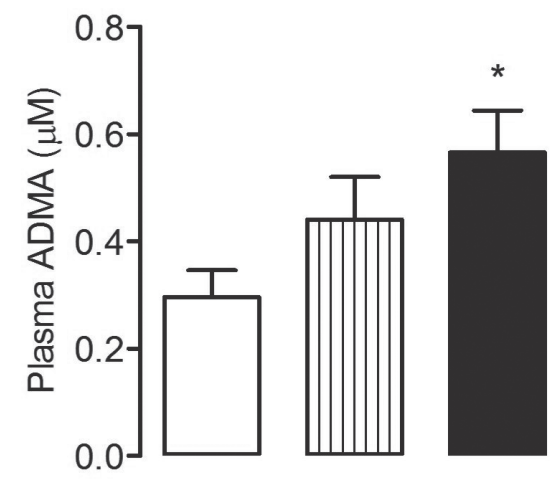

$\mathrm{D}$

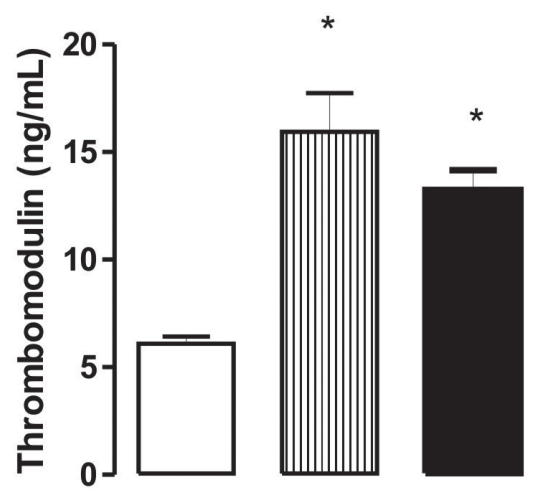

Fig. 2. Levels of L-arginine (A), ADMA (B), SDMA (C), and soluble thrombomodulin (D) in plasma of non-exposed, Cd-exposed and severely Cd-exposed subjects. Data are presented as mean \pm S.E. ${ }^{*} p<0.05$ vs. non-exposed group (ANOVA with Tukey's multiple comparison test).

were elevated in both Cd-exposed groups (exposed and severely exposed) than non-exposed group (mean \pm S.E.; $1.95 \pm 0.09,1.75 \pm 0.11$ vs. $0.29 \pm 0.01 \mu \mathrm{M}$, respectively; p < 0.05) (Fig. 3A). Similarly, the protein carbonyl groups in plasma of exposed and severely exposed were higher than non-exposed group (mean \pm S.E.; $1.36 \pm 0.10$, $1.15 \pm 0.10$ vs. $0.74 \pm 0.08 \mathrm{nmol} / \mathrm{mg}$ protein, respectively; $\mathrm{p}<0.05$ ) (Fig. 3B). Reduced glutathione concentrations in erythrocytes decreased in exposed and severely exposed compared with non-exposed group (mean \pm S.E.; $2277.3 \pm 126.9,2260.3 \pm 111.8$ vs. $3151.9 \pm 397.7 \mu \mathrm{M}$, respectively; $\mathrm{p}<0.05$ ) (Fig. 3C).

\section{Multiple regression analysis}

Multiple linear regression analysis was used to examine a correlation between endothelial function markers and $\mathrm{Cd}$ after adjusting other co-variables. Only urinary Cd was significantly related to erythrocytic nitrite levels (Table 2). Erythrocytic nitrite decreased $99.212 \mathrm{nM}$ for $1 \mu \mathrm{g} / \mathrm{g}$ creatinine increase in urinary $\mathrm{Cd}$. Age, blood pressure, serum lipid levels, blood $\mathrm{Cd}$, and urinary $\beta_{2}$-microglobulin showed no statistical relationship with 
A

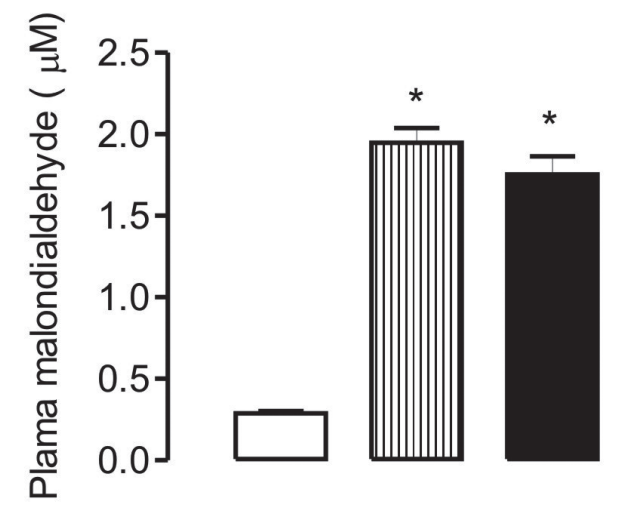

C

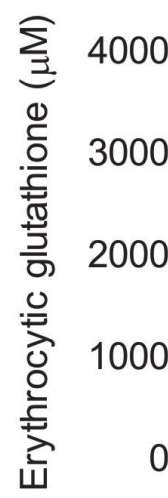
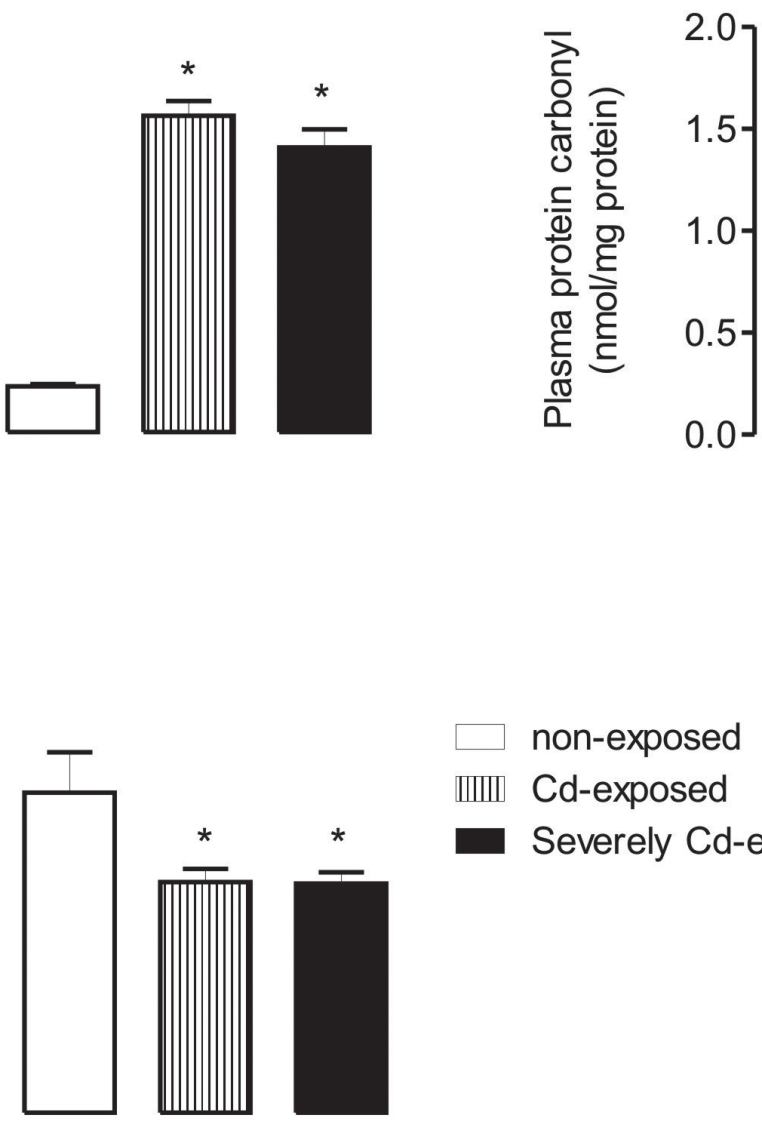

B

Fig. 3. Levels of plasma malondialdehyde (A) and protein carbonyl groups (B), and reduced glutathione in erythrocytes (C) of non-exposed, Cd-exposed and severely Cd-exposed subjects. Data are presented as mean \pm S.E. ${ }^{*} \mathrm{p}<0.05$ vs. non-exposed group (ANOVA with Tukey's multiple comparison test).

any markers of endothelial function.

\section{DISCUSSION}

Our study demonstrates a decrease in nitrite and increase in soluble thrombomodulin and ADMA in subjects with chronic $\mathrm{Cd}$ exposure. Plasma L-arginine decreased while ADMA increased in Cd-exposed subjects. The elevated levels of plasma malondialdehyde and protein carbonyl groups and a decrease in erythrocytic glutathione suggest the presence of oxidative stress. From multiple linear regression adjusting for age, blood pressure, lipid profile, blood $\mathrm{Cd}$, and urinary $\beta_{2}$-microglobulin, erythrocytic nitrite levels inversely correlated with urinary $\mathrm{Cd}$, but not with blood $\mathrm{Cd}$. Kidneys are the critical target organs of cadmium toxicity. Urinary Cd excretion is a good marker of long-term $\mathrm{Cd}$ exposure and body burden while blood Cd may represent recent exposure (Jarup et al., 1998; Gallagher and Meliker, 2010). Collectively, our findings suggest the endothelial dysfunction in $\mathrm{Cd}$ exposed subjects.

From our study, Cd-exposed subjects also show decreased HDL-C and increased triglyceride levels compared with non-exposed subjects. These results are consistent with the report that cadmium exposure is associated with the increased risk of low HDL-C and high triglycerides to HDL-C ratio in adults (Kim, 2012). However, in multiple regression analysis, HDL-C, triglycerides, age, and blood pressure were not related with erythrocytic nitrite and any endothelial markers. We speculate 
Endothelial dysfunction in Cd-exposed subjects

Table 2. Multiple linear regression analysis of the determinants of erythrocytic nitrite.

\begin{tabular}{lccc}
\hline \multirow{2}{*}{ Independent variables $^{\mathrm{a}}$} & \multicolumn{3}{c}{ Erythrocytic nitrite $(\mathrm{nM})^{\mathrm{p}}$} \\
\cline { 2 - 4 } Age & -0.042 & S.E. of $\beta$ & 0.953 \\
Mean arterial blood pressure & 0.214 & 0.701 & 0.781 \\
Total cholesterol & 148.661 & 0.764 & 0.198 \\
HDL-C & 0.201 & 113.422 & 0.820 \\
LDL-C & 0.343 & 0.880 & 0.072 \\
Triglycerides & 0.092 & 0.185 & 0.239 \\
Blood Cdc & 35.134 & 0.077 & 0.266 \\
Urinary Cdc & -99.212 & 31.060 & 0.004 \\
Urinary $\beta_{2}{ }^{\mathrm{b}}$-microglobulinc & -6.788 & 31.914 & 0.660
\end{tabular}

${ }^{\mathrm{a} A g e}$ (years), mean arterial blood pressure $(\mathrm{mmHg})$, total cholesterol $(\mathrm{mg} / \mathrm{dL})$, HDL-C (high-density lipoprotein cholesterol, $\mathrm{mg} / \mathrm{dL})$, LDL-C (low-density lipoprotein cholesterol, mg/dL), triglycerides $(\mathrm{mg} / \mathrm{dL})$, blood $\mathrm{Cd}(\mu \mathrm{g} / \mathrm{L})$, urinary Cd $(\mu \mathrm{g} / \mathrm{g}$ creatinine), and urinary $\beta_{2}$-microglobulin $(\mu \mathrm{g} / \mathrm{g}$ creatinine)

${ }^{\mathrm{b}}$ Regression coefficient.

cLog-transformed before analysis.

Adjusted $R^{2}=0.42$

that the exclusion of subjects with diabetes, hypertension and heart diseases may account for these findings.

Nitrite anion is a bioactive NO product circulating in blood. Although the source of nitrite is incompletely understood, its blood levels are believed to represent endothelial NO production (Lauer et al., 2001; Kleinbongard et al., 2003). In blood, nitrite is contained mostly in erythrocytes as unbound form in cytosol (Dejam et al., 2005). Thereby, the nitrite levels in erythrocytes may be an endothelial function marker that exhibit correlation with urinary cadmium. Shear stress and acetylcholine-induced eNOS activation increased blood nitrite and forearm blood flow in humans (Dejam et al., 2005). The biological effects of nitrite are NO-dependent vasodilation and platelet inhibition (Srihirun et al., 2012), which require bioactivation catalyzed by deoxygenated heme proteins or molybdopterin-containing proteins (Kim-Shapiro and Gladwin, 2014). Although lower nitrite concentrations suggest impaired vascular function in Cd-exposed subjects, further study on vascular reactivity such as measurement of forearm blood flow remains to be investigated. In contrast to nitrite, plasma nitrate was unchanged in Cd-exposed subjects. Nitrate is biologically inert and exists at high $\mu \mathrm{M}$ range in blood (Lauer et $a l ., 2001)$; thus, its levels are unlikely to reflect endothelial activity.

Plasma L-arginine was lower in Cd-exposed subjects than non-exposed subjects. The availability of L-arginine is essential for eNOS activity (Rochette et al., 2013).
Endothelial cells take up L-arginine via cationic amino acid transporters and may accumulate L-arginine within cells up to 0.8-2.0 mM (Pollock et al., 1991; Rochette et al., 2013). Despite high intracellular concentration of $\mathrm{L}$-arginine, its transport from plasma is required for NO synthesis. Nonetheless, the relationship of L-arginine and nitrite levels remains unclear.

NO is synthesized from L-arginine in endothelial cells by eNOS which is inhibited by ADMA. ADMA is a byproduct of protein degradation in cells and competes with L-arginine at the active site of eNOS (Vallance et al., 1992; Rochette et al., 2013). SDMA is not an eNOS inhibitor, but its high levels may compete with L-arginine for cellular uptake (Closs et al., 1997), thus indirectly reducing NO production. During the intracellular protein breakdown, ADMA and SDMA are produced by protein arginine N-methyltransferases (PRMTs) and released into the cytosol. ADMA may be accumulated in cells or exported into circulation via cationic amino acid transporter (Rochette et al., 2013). ADMA is taken up into cells and metabolized into citrulline by dimethylarginine dimethylaminohydrolases (DDAH) in liver and kidneys as the major route of elimination. Some amount of ADMA is excreted in urine. Oxidative stress increases PRMTs gene expression (Böger et al., 2000) but decreases DDAH activity (Ito et al., 1999), leading to ADMA accumulation and suppression of NO synthesis. Moreover, ADMA causes eNOS uncoupling, resulting in production of superoxide rather than NO (Antoniades et al., 2009). 
The raised ADMA levels are reported in diseases associated with endothelial dysfunction such as atherosclerosis, hypertension, diabetes mellitus, hyperlipidemia, ischemic heart disease, and chronic kidney disease (Valkonen et al., 2001; Lu et al., 2011).

Thrombomodulin is a transmembrane glycoprotein located on surface of endothelial cells, and functions as an anticoagulant. Thrombomodulin binds to thrombin, forming complex that inhibits fibrin formation, protein $\mathrm{S}$ inactivation and platelet activation (Conway, 2012). The complex also activates protein $\mathrm{C}$, leading to inactivation of clotting factor Va and VIIIa. Thrombomodulin is released from endothelial cells following cell injury (Ishii et al., 1991). Levels of soluble thrombomodulin are elevated in diseases associated with vascular injury such as vasculitis (Boehme et al., 1996), diabetes mellitus (Gabat et al., 1996) or nephrotic syndrome (Sharma et al., 2014). A rise in soluble thrombomodulin in Cd-exposed subjects suggests endothelial injury despite the lack of correlation between thrombomodulin and $\mathrm{Cd}$.

$\mathrm{Cd}$ has adverse effects on endothelial cells by several possible mechanisms. For example, $\mathrm{Cd}$ was shown to attenuate NO production in endothelial hybrid cell line by decreasing eNOS phosphorylation at serine 1177 (Majumder et al., 2008). Rats orally exposed to Cd exhibited hypertension which was associated with decreased eNOS protein levels (Yoopan et al., 2008). Cd altered endothelial cell integrity by disruption of cadherin-cadherin bonds, resulting in the increased permeability of vascular endothelium (Pearson et al., 2003). Cd exposure promoted NADPH oxidase expression in rat aorta, inducing oxidative stress in endothelial cells and impairing relaxation response to acetylcholine (Almenara et al., 2013). Oxidation of tetrahydrobiopterin $\left(\mathrm{BH}_{4}\right)$, a NOS cofactor, to $\mathrm{BH}_{2}$ uncouples eNOS (Vásquez-Vivar et al., 2003), leading to production of superoxide. Cd also induces endothelial cell death by several death pathways, thus promoting atherosclerosis (Messner et al., 2009; Messner and Bernhard, 2010).

Taken together, our results suggest that subjects with long-term $\mathrm{Cd}$ exposure exhibit endothelial dysfunction, which reinforces previous in vitro and in vivo (animal) findings that $\mathrm{Cd}$ induces endothelial damage. Further studies are needed to understand the pathway by which $\mathrm{Cd}$ affects endothelial cell function.

\section{ACKNOWLEDGMENTS}

This study was supported by grants from the Thailand Research Fund (RSA5580058), National Research Council of Thailand, and the Office of the Higher Education
Commission and Mahidol University under the National Research Universities Initiative.

Conflict of interest---- The authors declare that there is no conflict of interest.

\section{REFERENCES}

Abu-Hayyeh, S., Sian, M., Jones, K.G., Manuel, A. and Powell, J.T. (2001): Cadmium accumulation in aortas of smokers. Arterioscler. Thromb. Vasc. Biol., 21, 863-867.

Almenara, C.C., Broseghini-Filho, G.B., Vescovi, M.V., Angeli, J.K., Faria Tde, O., Stefanon, I., Vassallo, D.V. and Padilha, A.S. (2013): Chronic cadmium treatment promotes oxidative stress and endothelial damage in isolated rat aorta. PLoS One, 8, e68418.

Antoniades, C., Shirodaria, C., Leeson, P., Antonopoulos, A., Warrick, N., Van-Assche, T., Cunnington, C., Tousoulis, D., Pillai, R., Ratnatunga, C., Stefanadis, C. and Channon, K.M. (2009): Association of plasma asymmetrical dimethylarginine (ADMA) with elevated vascular superoxide production and endothelial nitric oxide synthase uncoupling: implications for endothelial function in human atherosclerosis. Eur. Heart J., 30, 1142-1150.

Beutler, E., Duron, O. and Kelly, B.M. (1963): Improved method for the determination of blood glutathione. J. Lab. Clin. Med., 61, 882-888.

Boehme, M.W., Schmitt, W.H., Youinou, P., Stremmel, W.R. and Gross, W.L. (1996): Clinical relevance of elevated serum thrombomodulin and soluble E-selectin in patients with Wegener's granulomatosis and other systemic vasculitides. Am. J. Med., 101, 387-394.

Böger, R.H., Bode-Böger, S.M., Szuba, A., Tsao, P.S., Chan, J.R., Tangphao, O., Blaschke, T.F. and Cooke, J.P. (1998): Asymmetric dimethylarginine (ADMA): a novel risk factor for endothelial dysfunction: its role in hypercholesterolemia. Circulation, 98, 1842-1847.

Böger, R.H., Sydow, K., Borlak, J., Thum, T., Lenzen, H., Schubert, B., Tsikas, D. and Bode-Böger, S.M. (2000): LDL cholesterol upregulates synthesis of asymmetrical dimethylarginine in human endothelial cells: involvement of S-adenosylmethionine-dependent methyltransferases. Circ. Res., 87, 99-105.

Bouman, A.C., Cheung, Y.W., Spronk, H.M., Schalkwijk, C.G., ten Cate, H., ten Wolde, M. and ten Cate-Hoek, A.J. (2014): Biomarkers for post thrombotic syndrome: a case-control study. Thromb. Res., 134, 369-375.

Closs, E.I., Basha, F.Z., Habermeier, A. and Förstermann, U. (1997): Interference of L-arginine analogues with L-arginine transport mediated by the $\mathrm{y}+$ carrier hCAT-2B. Nitric Oxide, 1, 65-73.

Conway, E.M. (2012): Thrombomodulin and its role in inflammation. Semin. Immunopathol., 34, 107-125.

Dejam, A., Hunter, C.J., Pelletier, M.M., Hsu, L.L., Machado, R.F., Shiva, S., Power, G.G., Kelm, M., Gladwin, M.T. and Schechter, A.N. (2005): Erythrocytes are the major intravascular storage sites of nitrite in human blood. Blood, 106, 734-739.

Donpunha, W., Kukongviriyapan, U., Sompamit, K., Pakdeechote, P., Kukongviriyapan, V. and Pannangpetch, P. (2011): Protective effect of ascorbic acid on cadmium-induced hypertension and vascular dysfunction in mice. Biometals, 24, 105-115.

Gabat, S., Keller, C., Kempe, H.P., Amiral, J., Ziegler, R., Ritz, E., 
Endothelial dysfunction in Cd-exposed subjects

Bergis, K.H., Wahl, P. and Nawroth, P. (1996): Plasma thrombomodulin: a marker for microvascular complications in diabetes mellitus. Vasa, 25, 233-241.

Gallagher, C.M. and Meliker, J.R. (2010): Blood and urine cadmium, blood pressure, and hypertension: a systematic review and meta-analysis. Environ. Health Perspect., 118, 1676-1684.

Ishii, H., Uchiyama, H. and Kazama, M. (1991): Soluble thrombomodulin antigen in conditioned medium is increased by damage of endothelial cells. Thromb. Haemost., 65, 618-623.

Ito, A., Tsao, P.S., Adimoolam, S., Kimoto, M., Ogawa, T. and Cooke, J.P. (1999): Novel mechanism for endothelial dysfunction: dysregulation of dimethylarginine dimethylaminohydrolase. Circulation, 99, 3092-3095.

Jarup, L., Berglund, M., Elinder, C.G., Nordberg, G. and Vahter, M. (1998): Health effects of cadmium exposure--a review of the literature and a risk estimate. Scand. J. Work Environ. Health, 24 Suppl 1, 1-51.

Kim-Shapiro, D.B. and Gladwin, M.T. (2014): Mechanisms of nitrite bioactivation. Nitric Oxide, 38, 58-68.

Kim, K. (2012): Blood cadmium concentration and lipid profile in Korean adults. Environ. Res., 112, 225-229.

Kleinbongard, P., Dejam, A., Lauer, T., Rassaf, T., Schindler, A., Picker, O., Scheeren, T., Gödecke, A., Schrader, J., Schulz, R., Heusch, G., Schaub, G.A., Bryan, N.S., Feelisch, M. and Kelm, M. (2003): Plasma nitrite reflects constitutive nitric oxide synthase activity in mammals. Free Radic. Biol. Med., 35, 790-796.

Lauer, T., Preik, M., Rassaf, T., Strauer, B.E., Deussen, A., Feelisch, M. and Kelm, M. (2001): Plasma nitrite rather than nitrate reflects regional endothelial nitric oxide synthase activity but lacks intrinsic vasodilator action. Proc. Natl. Acad. Sci. USA, 98, 12814-12819.

Lu, T.M., Chung, M.Y., Lin, C.C., Hsu, C.P. and Lin, S.J. (2011): Asymmetric dimethylarginine and clinical outcomes in chronic kidney disease. Clin. J. Am. Soc. Nephrol., 6, 1566-1572.

Majumder, S., Muley, A., Kolluru, G.K., Saurabh, S., Tamilarasan, K.P., Chandrasekhar, S., Reddy, H.B., Purohit, S. and Chatterjee, S. (2008): Cadmium reduces nitric oxide production by impairing phosphorylation of endothelial nitric oxide synthase. Biochem. Cell. Biol., 86, 1-10.

Messner, B. and Bernhard, D. (2010): Cadmium and cardiovascular diseases: cell biology, pathophysiology, and epidemiological relevance. Biometals, 23, 811-822.

Messner, B., Knoflach, M., Seubert, A., Ritsch, A., Pfaller, K., Henderson, B., Shen, Y.H., Zeller, I., Willeit, J., Laufer, G., Wick, G., Kiechl, S. and Bernhard, D. (2009): Cadmium is a novel and independent risk factor for early atherosclerosis mechanisms and in vivo relevance. Arterioscler. Thromb. Vasc. Biol., 29, 1392-1398.

Ohkawa, H., Ohishi, N. and Yagi, K. (1979): Assay for lipid peroxides in animal tissues by thiobarbituric acid reaction. Anal. Biochem., 95, 351-358.

Pearson, C.A., Lamar, P.C. and Prozialeck, W.C. (2003): Effects of cadmium on E-cadherin and VE-cadherin in mouse lung. Life Sci., 72, 1303-1320.

Pelletier, M.M., Kleinbongard, P., Ringwood, L., Hito, R., Hunter, C.J., Schechter, A.N., Gladwin, M.T. and Dejam, A. (2006): The measurement of blood and plasma nitrite by chemiluminescence: pitfalls and solutions. Free Radic. Biol. Med., 41, 541-548.

Pollock, J.S., Förstermann, U., Mitchell, J.A., Warner, T.D., Schmidt, H.H., Nakane, M. and Murad, F. (1991): Purification and characterization of particulate endothelium-derived relaxing factor synthase from cultured and native bovine aortic endothelial cells. Proc. Natl. Acad. Sci. USA, 88, 10480-10484.

Prozialeck, W.C. and Edwards, J.R. (2010): Early biomarkers of cadmium exposure and nephrotoxicity. Biometals, 23, 793-809.

Rochette, L., Lorin, J., Zeller, M., Guilland, J.C., Lorgis, L., Cottin, Y. and Vergely, C. (2013): Nitric oxide synthase inhibition and oxidative stress in cardiovascular diseases: possible therapeutic targets? Pharmacol. Ther., 140, 239-257.

Sharma, B., Saha, A., Dubey, N.K., Kapoor, K., Anubhuti, Batra, V. V. and Upadhayay, A.D. (2014): Endothelial dysfuntion in children with idiopathic nephrotic syndrome. Atherosclerosis, 233, 704-706.

Srihirun, S., Sriwantana, T., Unchern, S., Kittikool, D., Noulsri, E., Pattanapanyasat, K., Fucharoen, S., Piknova, B., Schechter, A.N. and Sibmooh, N. (2012): Platelet inhibition by nitrite is dependent on erythrocytes and deoxygenation. PLoS One, 7, e30380.

Swaddiwudhipong, W., Limpatanachote, P., Mahasakpan, P., Krintratun, S., Punta, B. and Funkhiew, T. (2012): Progress in cadmium-related health effects in persons with high environmental exposure in northwestern Thailand: a five-year followup. Environ. Res., 112, 194-198.

Teerlink, T., Nijveldt, R.J., de Jong, S. and van Leeuwen, P.A. (2002): Determination of arginine, asymmetric dimethylarginine, and symmetric dimethylarginine in human plasma and other biological samples by high-performance liquid chromatography. Anal. Biochem., 303, 131-137.

Tellez-Plaza, M., Guallar, E., Howard, B.V., Umans, J.G., Francesconi, K.A., Goessler, W., Silbergeld, E.K., Devereux, R. B. and Navas-Acien, A. (2013): Cadmium exposure and incident cardiovascular disease. Epidemiology, 24, 421-429.

Tohda, G., Oida, K., Okada, Y., Kosaka, S., Okada, E., Takahashi, S., Ishii, H. and Miyamori, I. (1998): Expression of thrombomodulin in atherosclerotic lesions and mitogenic activity of recombinant thrombomodulin in vascular smooth muscle cells. Arterioscler. Thromb. Vasc. Biol., 18, 1861-1869.

Tripepi, G., Mattace Raso, F., Sijbrands, E., Seck, M.S., Maas, R., Boger, R., Witteman, J., Rapisarda, F., Malatino, L., Mallamaci, F. and Zoccali, C. (2011): Inflammation and asymmetric dimethylarginine for predicting death and cardiovascular events in ESRD patients. Clin. J. Am. Soc. Nephrol., 6, 1714-1721.

Valkonen, V.P., Päivä, H., Salonen, J.T., Lakka, T.A., Lehtimaki, T., Laakso, J. and Laaksonen, R. (2001): Risk of acute coronary events and serum concentration of asymmetrical dimethylarginine. Lancet, 358, 2127-2128.

Vallance, P., Leone, A., Calver, A., Collier, J. and Moncada, S. (1992): Accumulation of an endogenous inhibitor of nitric oxide synthesis in chronic renal failure. Lancet, 339, 572-575.

Vásquez-Vivar, J., Kalyanaraman, B. and Martásek, P. (2003): The role of tetrahydrobiopterin in superoxide generation from eNOS: enzymology and physiological implications. Free Radic. Res., 37, 121-127.

Yang, B.K., Vivas, E.X., Reiter, C.D. and Gladwin, M.T. (2003): Methodologies for the sensitive and specific measurement of S-nitrosothiols, iron-nitrosyls, and nitrite in biological samples. Free Radic. Res., 37, 1-10.

Yoopan, N., Watcharasit, P., Wongsawatkul, O., Piyachaturawat, P. and Satayavivad, J. (2008): Attenuation of eNOS expression in cadmium-induced hypertensive rats. Toxicol. Lett., 176, 157161. 